УДК 511.3

\title{
Александр Александрович Фомин \\ (к 70-летию со дня рождения)
}

В. Н. Чубариков, Н. М. Добровольский, В. А. Артамонов, А. В. Михалев, В. Н. Латышев, Ю. В. Нестеренко, А. Я. Белов, А. В. Гришин, Е. И. Компанцева, А. В. Царев, Е. И. Деза, П. А. Крылов, А. А. Туганбаев

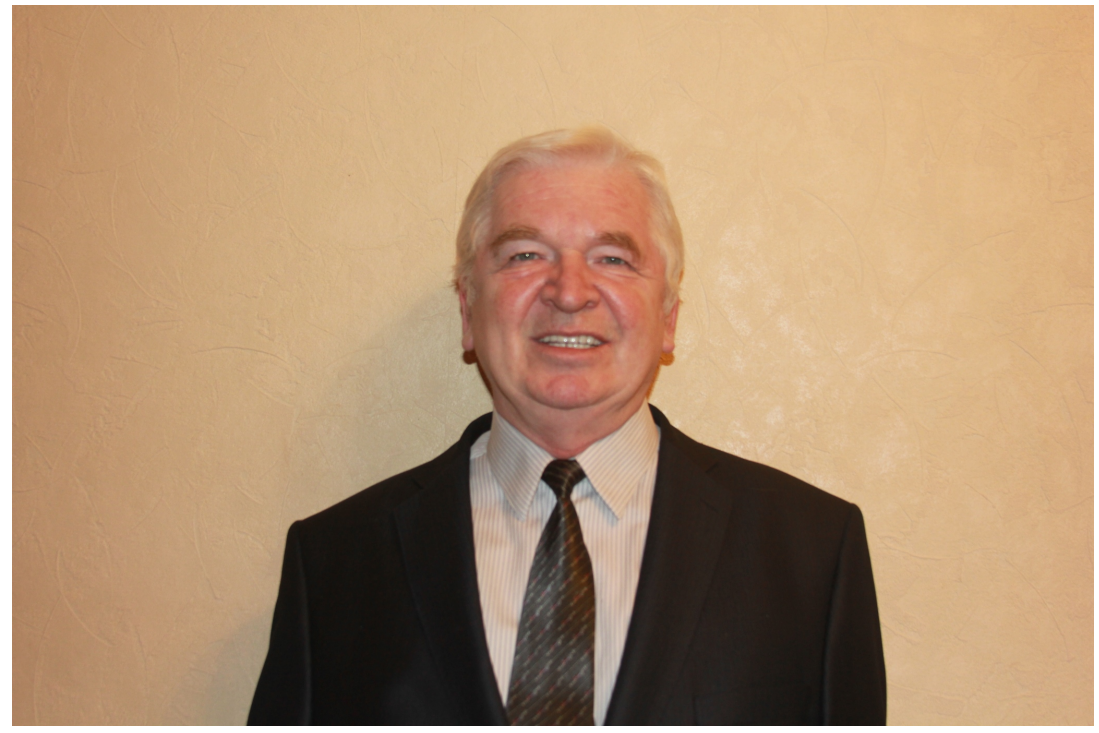

Александр Александрович Фомин родился 4 мая 1949 года в деревне Александровка Красногорского района Московской области в семье участников войны, которые познакомились на фронте. Отец, Александр Андреевич Фомин (1917-1989), работал в Военно-воздушной инженерной академии им. Н. Е. Жуковского. Мать, Евгения Ивановна Фомина (1922-2007), работала главным бухгалтером Росбытнот. Она была внучкой известного Павлопосадского художника Константина Егоровича Аболихина (1868-1942).

Александр увлекся математикой благодаря учителю московской средней школы № 150 Юрию Васильевичу Черемисину и руководителю кружка при МГУ Леониду Насоновичу Вассерштейну. В результате он поступает в 9-й класс математической школы № 2, которую оканчивает в 1966 году с серебряной медалью. В этой школе лекции по математике читал профессор МГУ Евгений Борисович Дынкин, а практические занятия вел доцент МГУ Александр Дмитриевич Вентцель.

После окончания школы А. А. Фомин продолжает обучение на математическом факультете Московского государственного педагогического института им. В. И. Ленина (ныне - Московский педагогический государственный университет). В 1971 году он с отличием закончил институт и был оставлен в аспирантуре под руководством заведующего кафедрой алгебры профессора Леонида Яковлевича Куликова. С 1974 года и по настоящее время Александр Александрович работает на кафедре алгебры МПГУ, являясь заведующим этой кафедрой с 1989 года. Помимо работы в МПГУ, А. А. Фомин много работал по приглашению университетов различных стран: в США, в Германии, в Турции и в Колумбии.

В 1976 году А. А. Фомин защитил кандидатскую диссертацию на тему «Тензорное произведение абелевых групп без кручения». В этой диссертации были вычислены матрицы КурошаДэрри тензорного произведения двух абелевых групп без кручения конечного ранга по матрицам сомножителей и исследованы тензорные степени абелевой группы без кручения конечного ранга [1]. 
Продолжая математические исследования, А. А. Фомин вводит и изучает такие классы абелевых групп без кручения конечного ранга, как группы, у которых любая подгруппа бесконечного индекса свободна [2], группы, у которых любая собственная сервантная подгруппа свободна [3], группы с одним $\tau$-адическим соотношением [4] и группы ранга 3 [5].

В 1992 году А. А. Фомин защитил докторскую диссертацию на тему «Абелевы группы без кручения конечного ранга с точностью до квазиизоморфизма». В этой диссертации были введены $\tau$-адические числа и показано, что для изучения коредуцированных абелевых групп без кручения конечного ранга можно использовать аппарат конечно порожденных модулей над кольцами $\tau$-адические чисел [6].

Вся научная работа А. А. Фомина посвящена теории абелевых групп - области математики, в которой он является одним из ведущих специалистов в мире. Ему принадлежит заслуга в привлечении внимания к смешанным факторно делимым группам. Напомним, что абелева группа $A$ называется факторно делимой, если она не содержит ненулевых делимых периодических подгрупп, но содержит такую свободную подгруппу $F$ конечного ранга, что $A / F$ - делимая периодическая группа. Вместе с американским алгебраистом У. Уиклессом они доказали, что категория факторно делимых групп с квазигомоморфизмами в качестве морфизмов двойственна категории квазигомоморфизмов абелевых групп без кручения конечного ранга [7]. Факторно делимые группы без кручения были впервые рассмотрены Р. Бьюмонтом и Р. Пирсом [8] при изучении аддитивных групп колец без элементов конечного порядка.

В настоящее время класс факторно делимых групп - один из самых исследуемых в теории абелевых групп. Александр Александрович разработал аппарат для изучения этого класса $[9,10]$. Им, в частности, доказана следующая красивая теорема.

Теорема о вложении [10]. Пусть $A-$ группа с конечной максимальной линейно независимой над $\mathbb{Z}$ системой элементов $a_{1}, \ldots, a_{n}$, не содержсащая ненулевых периодических делимых подгрупп, и пусть $\mu: A \rightarrow \widehat{A}-\mathbb{Z}$-адическое пополнение группы $A$. Тогда группа $A$ является факторно делимой с базисом $a_{1}, \ldots, a_{n}$ в том и толъко том случае, когда элементы $\mu\left(a_{1}\right), \ldots, \mu\left(a_{n}\right)$ порождают $\widehat{A}$ как модуль над кольцом полиадических чисел $\widehat{\mathbb{Z}}$.

Данная теорема позволяет использовать для изучения факторно делимых групп аппарат конечно порожденных модулей над кольцом полиадических чисел. Вообще, А. А. Фомин очень плодотворно использует для исследования абелевых групп их различные модульные оболочки. Так, при работе с группами без кручения конечного ранга, он использует конечно порожденные модули над кольцами $\tau$-адических чисел. А при исследовании факторно делимых групп, наряду с модулями над кольцом полиадических чисел, А. А. Фомин также применяет конечно порожденные модули над кольцом псевдорациональных чисел [11]. В связи с этим им были разработаны основные положения теории модулей над кольцами полиадических и псевдорациональных чисел и над некоторыми другими близкими к ним кольцами $[12,13]$. Надо сказать, что подход к изучению абелевых групп, основанный на применении определенных модулей ассоциированных с данной группой, является весьма актуальным и перспективным в теории абелевых групп. В этом плане очень важны $p$-адические модули, т. е. модули над кольцами целых $p$-адических чисел. Собственно, Александр Александрович обобщил и развил эту классическую ситуацию. Ведь кольцо полиадических чисел и кольцо псевдорациональных чисел определенным образом конструируются из колец целых р-адических чисел.

Эти и другие результаты Александра Александровича изложены в монографии известного американского математика Ласло Фукса [14]. Обзоры научных работ А. А. Фомина можно также найти в статьях $[15,16]$.

Отметим, что помимо научной работы, А. А. Фомин много лет занимался математическими олимпиадами школьников и студентов. В частности, он руководил командой СССР (a затем России) на Международной математической олимпиаде школьников с 1984 по 1994 год. Под его руководством команда школьников СССР четыре раза становилась чемпионом мира 
на олимпиадах в Чехословакии в 1984 году, в Польше в 1986 году (поделила первое место с командой США), в Австралии в 1988 году и в Швеции в 1991 году. Александр Александрович неоднократно участвовал в Международном математическом соревновании студентов университетов в качестве руководителя команды Колумбии и команды МПГУ. В 2013 году он входил в оргкомитет 54-й Международной математической олимпиады в городе Санта-Марта (Колумбия) в качестве координатора.

В течение ряда лет А. А. Фомин участвовал в подготовке заданий по математике для ЕГЭ. Начиная с 2014 года, А. А. Фомин входит в состав Экспертного совета ВАК по математике и механике.

Редакционная коллегия журнала «Чебышевский сборник», кафедра алгебры, математического анализа и геометрии Тульского государственного педагогического университета им. Л. Н. Толстого, кафедра алгебры МПГУ, кафедра высшей алгебры МГУ, кафедра алгебры Томского государственного университета поздравляют заведующего кафедрой алгебры Московского государственного педагогического университета, доктора физико-математических наук, профессора Александра Александровича Фомина с семидесятилетием. Мы желаем нашему коллеге крепкого здоровья и дальнейших успехов в научной и педагогической деятельности.

\section{СПИСОК ЦИТИРОВАННОЙ ЛИТЕРАТУРЫ}

1. А. А. Фомин, Тензорное произведение абелевых групп без кручения // Сиб. матем. журн. - 1975. - T. 16 , № 4. - C. 869-878.

2. А. А. Фомин, Абелевы группы со свободными подгруппами бесконечного индекса и их кольца эндоморфизмов // Матем. заметки. - 1984. - Т. 36, № 2. - С. 179-187.

3. А. А. Фомин, Сервантно свободные группы // Абелевы группы и модули. - Томск, 1986. C. $145-164$.

4. А. А. Фомин, Абелевы группы с одним $\tau$-адическим соотношением // Алгебра и логика. 1989. - Т. 28 , № 1. - C. 83-104.

5. А. А. Фомин, Абелевы группы без кручения ранга 3 // Матем. сб. - 1989. - Т. 180, № 9. C. $1155-1170$.

6. A. A. Fomin, The category of quasi-homomorphisms of Abelian torsion-free groups of finite rank // Proc. of the Internat. Conf. on Algebra Dedicated to the Memory of A.I. Mal'cev. Pt. 1. Providence: Amer. Math. Soc., 1992. - (Contemp. Math.; Vol. 131). - P. 91-111.

7. A. A. Fomin, W. J. Wickless, Quotient divisible Abelian groups // Proc. Amer. Math. Soc. 1998. - Vol. 126, no. 1. - P. 45-52.

8. R. Beaumont, R. Pierce. Torsion free rings // Illinois J. Math. - 1961. - Vol. 5. - P. 61-98.

9. А. А. Фомин, K теории факторно делимых групп. I // Фундамент. и прикл. матем. 2011/2012. - Т. 17, вып. 8. - С. 153-167.

10. А. А. Фомин, K теории факторно делимых групп. II // Фундамент. и прикл. матем. -2015. - Т. 20, вып. 5. - С. 157-196

11. A. A. Fomin, Some mixed Abelian groups as modules over the ring of pseudo-rational numbers // Abelian Groups and Modules. Int. Conf. in Dublin, August 10-14, 1998. - Basel: Birkhauser, 1999. - (Trends Math.). - P. 87-100. 
12. A. A. Fomin, Finitely presented modules over the ring of universal numbers // Abelian Group Theory and Related Topics. Conf. on Abelian Groups. August 1-7, 1993. Oberwolfach, Germany. - Providence: Amer. Math. Soc., 1994. - (Contemp. Math.; Vol. 171). - P. 109-120.

13. А. А. Фомин, Числовые кольца и модули над ними. - М.: МПГУ, Прометей, 2013.

14. L. Fuchs, Abelian groups. - Springer, Switzerland, 2015.

15. Александр Александрович Фомин. K 65-летию со дня рождения // Фундамент. и прикл. матем. - 2015. - Т. 20, вып. 5. - С. 3-9.

16. A. A. Fomin, Abelian groups in Russia // Rocky Mountain J. Math. - 2002. - Vol. 32, no. 4. - P. 1161-1180.

Получено 18.03.2019 г.

Принято в печать 12.07.2019 г. 